\title{
APPROACHES FOR EVALUATING FAILURE PROBABILITY OF EMERGENCY POWER SUPPLY SYSTEMS IN HOSPITALS
}

\author{
CHI-HAO LIN, XIAOQIN LIU, CHENG-TAO YANG, YI-KUANG PAN \& YU-CHIA LIAO \\ National Center for Research on Earthquake Engineering, Taiwan.
}

\begin{abstract}
The unpredictable feature of earthquake is one of the major reasons for building damages and casualties occurring in earthquake events. Despite earthquake-induced structural damages to buildings, ground shaking can also impose critical effects on nonstructural components and systems in buildings. This study aimed to develop a probability-based approach for evaluating seismic damages to emergency power supply systems (EPSSs) in Taiwanese hospitals. For this purpose, four case hospitals that were somewhat damaged in the Chi-Chi earthquake (September 21, 1999) were investigated, and the component scoring system developed by the Multidisciplinary Center for Earthquake Engineering Research in the United States was referenced as the basis for developing seismic fragility curves for the components in the EPSSs of the case hospitals. Additionally, the logic tree method was employed to evaluate the failure probability of the EPSSs. The results exhibited acceptable consistency with the recorded damage status of the investigated systems, thereby verifying the feasibility of the proposed approach.
\end{abstract}

Keywords: emergency power system, failure probability, logic tree, seismic fragility

\section{INTRODUCTION}

First-aid hospitals are critical facilities that play an important role in receiving injured patients and performing emergency operations during severe earthquake events. Therefore, hospitals must maintain not only the safety of their building structures but also ensure the functionality of their nonstructural components and systems. These include emergency power supply systems (EPSSs), water supply systems, communication systems, and a range of medical equipment for patient care. Records of past earthquake disasters such as the 1971 San Fernando earthquake, 1994 Northridge earthquake, 1995 Hanshin earthquake, 1999 Chi-Chi earthquake indicate that many hospitals could not provide medical services because of severe nonstructural damage. In particular, EPSS is the most important system, because it provides electric power for other equipment and systems.

In this study we focused on a failure probability analysis of EPSSs. There are several approaches to assessing failure probability. Our methodology involved applying a system logic tree, assessing component fragility data and site hazards. After the Chi-Chi Earthquake in Taiwan, Chuang et al. investigated four severely damaged hospitals [1]. They constructed logic trees for the EPSSs for these hospitals. Five types of emergency power supply component (EPSC) are involved in an EPSS, namely a control panel (CP), a generator $(\mathrm{G})$, a battery rack (BR), a diesel tank (DT) and a cooling tower (CT). The seismic fragility function of these components was studied based on the component seismic scoring system developed by the Multidisciplinary Center for Earthquake Engineering Research (MCEER) [2-3]. We utilized logic trees to estimate the failure probabilities of the EPSSs on the basis of the peak ground acceleration (PGA) of the hospital sites, and then verified the suitability of the methodology. 


\section{FRAGILITY DATA OF EMERGENCY POWER SUPPLY COMPONENTS}

In earthquake engineering, fragility is usually used to quantify the failure probability of structures and nonstructures. In this study, we applied PGA as the ground-motion parameter because it can be easily and accurately measured. The component fragility was assumed to be a two-parameter lognormal distribution function with median $x_{m}$ and log-standard deviation $\beta$, as shown in eqn (1).

$$
P(\alpha)=\Phi\left[\frac{\ln \left(\alpha / x_{m}\right)}{\beta}\right]
$$

where $P$ denotes the failure probability, $\Phi[\cdot]$ is the standardized normal distribution and $\alpha$ is the ground-motion parameter, e.g. PGA.

In our previous study based on MCEER, we proposed fragility data for EPSCs [3]. These fragility data are considered to provide not only high standards for installation but also to function as performance modification factors (PMFs). PMFs describe a variety of poor installation cases for nonstructural components. Tables 1-5 show the fragility data for EPSCs. The PMF descriptions reference the seismic score sheets developed by MCEER. $x_{m}$ and $\beta$ were originally proposed by MCEER for the high-standard installation of each component [2]. In our study, the fragility data for each PMF were identified to accurately estimate the damage probabilities of EPSCs. $x_{m}$ has a markedly higher value under the high-standard installation. This indicates that the component has a high seismic capacity. If the component has an installation deficiency, $x_{m}$ is significantly reduced.

Table 1: Parameters of seismic fragility data for control panels.

\begin{tabular}{lllll}
\hline \multicolumn{2}{l}{ Control panel } & & $x_{m}$ & $\beta$ \\
\hline high-standard installation & & 2.3 & 0.4 \\
\hline \multicolumn{6}{c}{ PMF1 } & No anchorage & 0.58 & 0.5 \\
& PMFs & Poor anchorage & 0.67 & 0.5 \\
& PMF2 & Suspect load path & 0.58 & 0.5 \\
& PMF3 & Pounding or impact concerns & 1.22 & 0.5 \\
& PMF5 & Inflexible concerns & 0.58 & 0.5 \\
& PMF6 & Interaction concerns & 0.46 & 0.5 \\
\hline
\end{tabular}

Table 2: Parameters of seismic fragility curves for generators.

\begin{tabular}{|c|c|c|c|c|}
\hline \multicolumn{3}{|c|}{ Generator } & $x_{m}$ & $\beta$ \\
\hline \multicolumn{3}{|c|}{ high-standard installation } & 2.0 & 0.4 \\
\hline \multirow{6}{*}{ PMFs } & PMF1 & No anchorage & 0.78 & 0.5 \\
\hline & PMF2 & Poor anchorage & 0.91 & 0.5 \\
\hline & PMF3 & Vibration isolator concerns & 0.91 & 0.5 \\
\hline & PMF4 & Rigid attachment concerns & 0.58 & 0.5 \\
\hline & PMF5 & Driver/generator diff. displacement & 0.58 & 0.5 \\
\hline & PMF6 & Interaction concerns & 0.91 & 0.5 \\
\hline
\end{tabular}


Table 3: Parameters of seismic fragility data for battery racks.

\begin{tabular}{|c|c|c|c|c|}
\hline \multicolumn{3}{|c|}{ Battery rack } & $x_{m}$ & $\beta$ \\
\hline \multicolumn{3}{|c|}{ high-standard installation } & 2.5 & 0.4 \\
\hline \multirow{6}{*}{ PMFs } & PMF1 & No anchorage & 0.67 & 0.5 \\
\hline & PMF2 & Poor anchorage & 0.78 & 0.5 \\
\hline & PMF3 & No battery spacers & 0.67 & 0.5 \\
\hline & PMF4 & No longitudinal cross-bracing & 0.78 & 0.5 \\
\hline & PMF5 & No battery restraints & 0.58 & 0.5 \\
\hline & PMF6 & Interaction concerns & 0.58 & 0.5 \\
\hline
\end{tabular}

Table 4: Parameters of seismic fragility data for diesel tanks.

\begin{tabular}{|c|c|c|c|c|}
\hline \multicolumn{3}{|c|}{ Diesel tank } & $x_{m}$ & $\beta$ \\
\hline \multicolumn{3}{|c|}{ high-standard installation } & 1.6 & 0.5 \\
\hline \multirow{4}{*}{ PMFs } & PMF1 & $\begin{array}{l}\text { Tank is unanchored or the anchorage is in poor } \\
\text { condition. }\end{array}$ & 0.56 & 0.5 \\
\hline & PMF2 & If anchored to a skid, the skid is unanchored. & 0.89 & 0.5 \\
\hline & PMF3 & $\begin{array}{l}\text { Attached piping is too rigid to withstand expected } \\
\text { displacement. }\end{array}$ & 0.71 & 0.5 \\
\hline & PMF4 & $\begin{array}{l}\text { Legs appear to be undersized for weight of the tank, } \\
\text { or skirt has unreinforced opening. }\end{array}$ & 0.71 & 0.5 \\
\hline
\end{tabular}

Table 5: Parameters of seismic fragility data for cooling towers.

\begin{tabular}{|c|c|c|c|c|}
\hline \multicolumn{3}{|c|}{ Cooling tower } & $x_{m}$ & $\beta$ \\
\hline \multicolumn{3}{|c|}{ high-standard installation } & NA & NA \\
\hline \multirow{3}{*}{ PMFs } & PMF1 & $\begin{array}{l}\text { Cooling tower is unanchored or the anchorage is } \\
\text { in poor condition. }\end{array}$ & 0.46 & 0.5 \\
\hline & PMF2 & If anchored to a skid, the skid is unanchored. & 0.91 & 0.5 \\
\hline & PMF3 & Rigid attachment concerns & 0.46 & 0.5 \\
\hline
\end{tabular}

\section{FAILURE PROBABILITY OF EMERGENCY POWER SUPPLY SYSTEMS}

On September 21, 1999 at 1:47 am local time an earthquake measuring 7.3 on the Richter scale occurred in central Taiwan. Its epicenter was at $23.87^{\circ} \mathrm{N} 120.75^{\circ} \mathrm{E}$ in Chi-Chi Township of Nantou County and located at a depth of only $7.0 \mathrm{~km}$. The earthquake originated along the Chelungpu fault line in western Taiwan and caused substantial damage. This incident was subsequently named 'the Chi-Chi earthquake.'

Chuang et al. investigated the four first-aid hospitals (A-D) that were damaged in Nantou County [1]. Figure 1 shows a seismic intensity map of the Chi-Chi earthquake and the location of the four hospitals. The maximum PGA was approximately $1 g$. Table 6 shows the PGA at the four hospitals. The Chelungpu fault is a reverse fault. Hospital D was located on the 


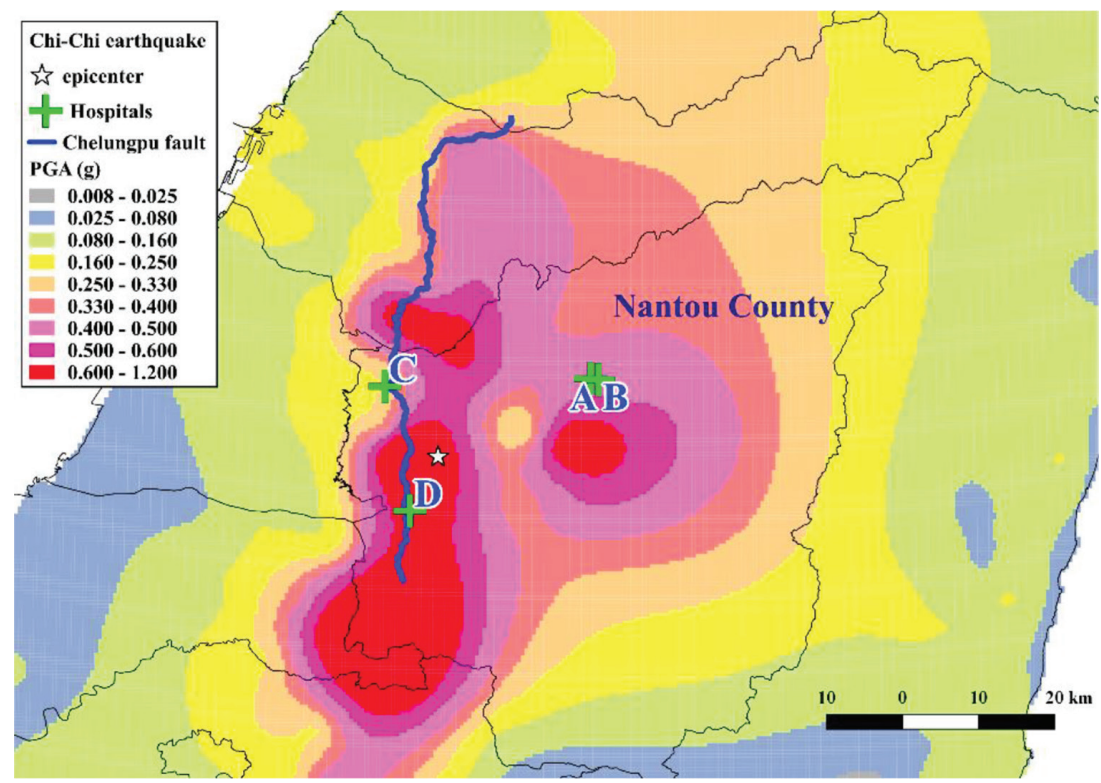

Figure 1: Seismic intensity map of the Chi-Chi earthquake and the location of the four hospitals.

Table 6: PGA values of the four hospitals in the Chi-Chi earthquake.

\begin{tabular}{lllll}
\hline & A & B & C & D \\
\hline PGA (g) & 0.45 & 0.45 & 0.28 & 0.67 \\
\hline
\end{tabular}

hanging wall and near the fault, only a short distance from the epicenter. Thus, it experienced a considerable ground motion. Although hospital $\mathrm{C}$ was also near the fault, it was located on the foot wall. Thus, the ground motion it experienced was not substantial. Hospitals A and B were adjacent and experienced the same ground-motion intensity.

\subsection{System logic tree}

Logic trees are graphical descriptions of the logical dependencies between systems and their subcomponents [4-5]. Mathematically, upper events are connected to lower events through an 'and' gate (symbol: $\bullet$ ) or an 'or' gate (symbol: $\diamond)$. Equation (2) provides the probability for the upper event through an 'and' gate. For an 'or' gate, the probability of the upper event can be derived using eqn (3).

$$
\begin{gathered}
P[u]=1-\prod_{i=1}^{n}\left(1-P\left[l_{i}\right]\right) \\
P[u]=\prod_{i=1}^{n} P\left[l_{i}\right]
\end{gathered}
$$

where $P$ denotes the failure probability, $u$ represents the upper event, $l_{i}$ are the lower events for the component and $\prod$ denotes the product. 
Figure 2 shows a logic tree diagram of the EPSSs in the hospitals. Only the EPSS in hospital $\mathrm{C}$ had no cooling tower; the other hospitals had the five major components. The floor where the component was located is indicated in parentheses in the figure. B1 refers to the basement first floor. RF denotes the roof floor. The EPSSs in hospitals A and B differ in that

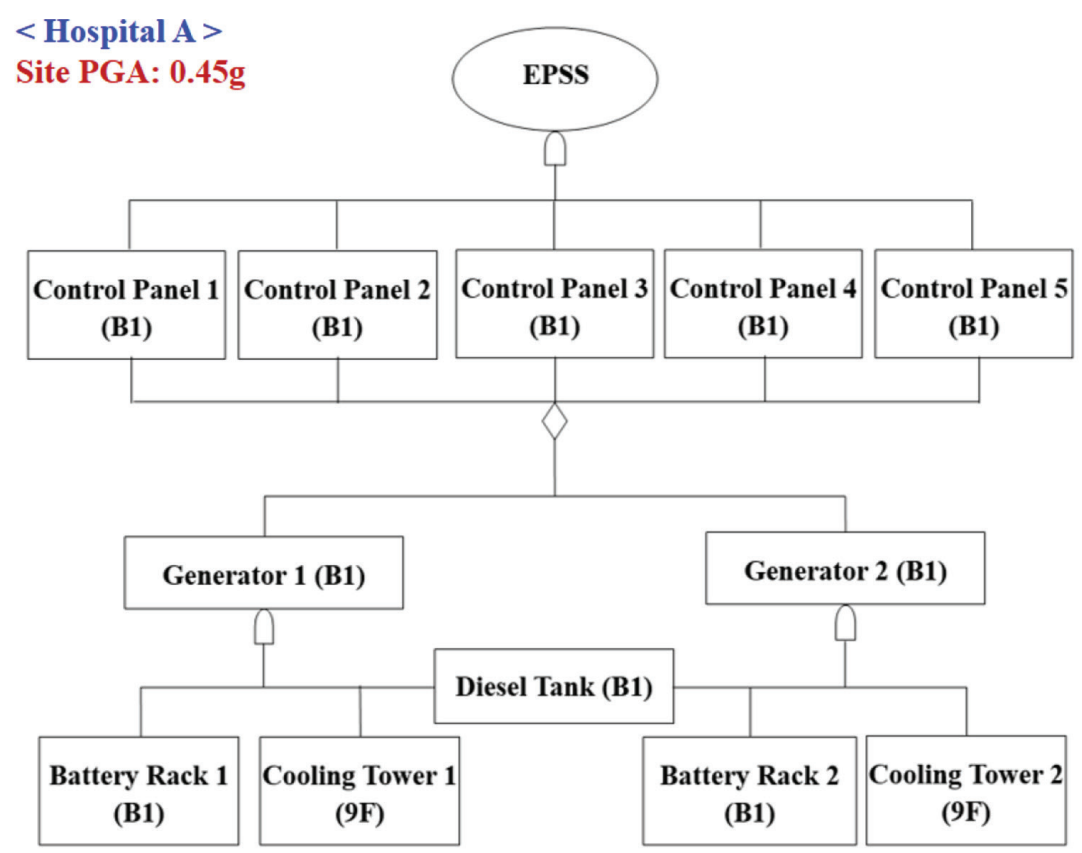

$<$ Hospital B >

Site PGA: 0.45g

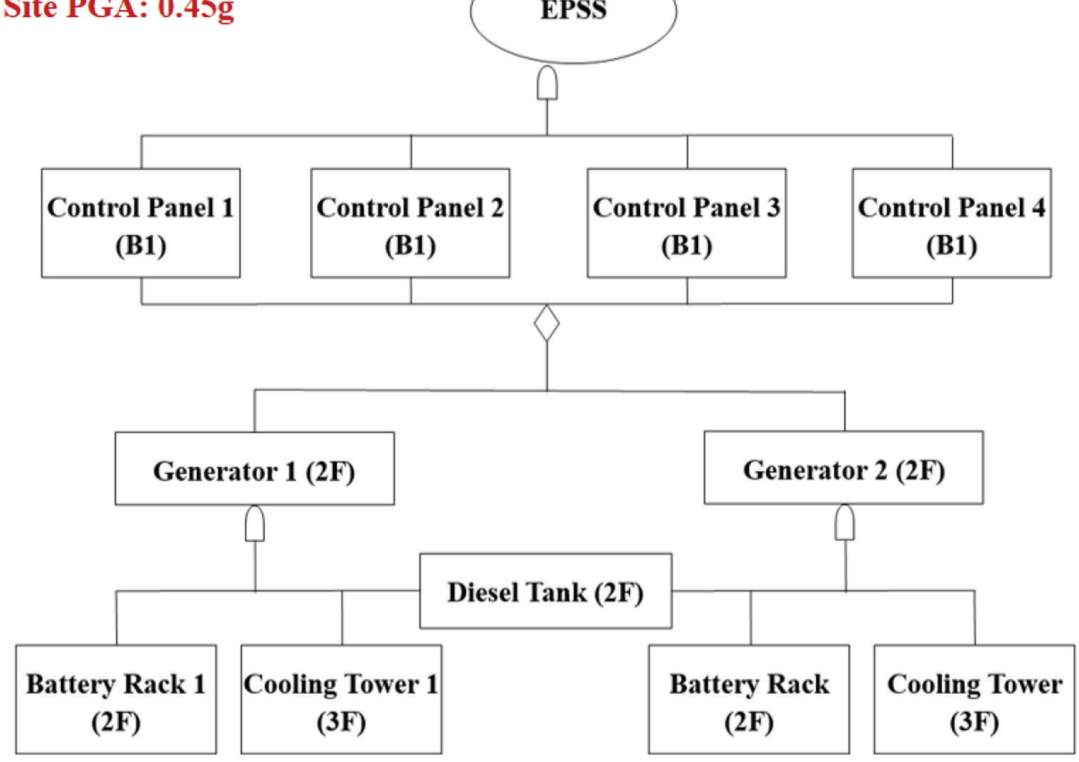

Figure 2: Logic tree diagrams of the EPSSs in Hospitals A - D. 
$<$ Hospital C >

Site PGA: 0.28g

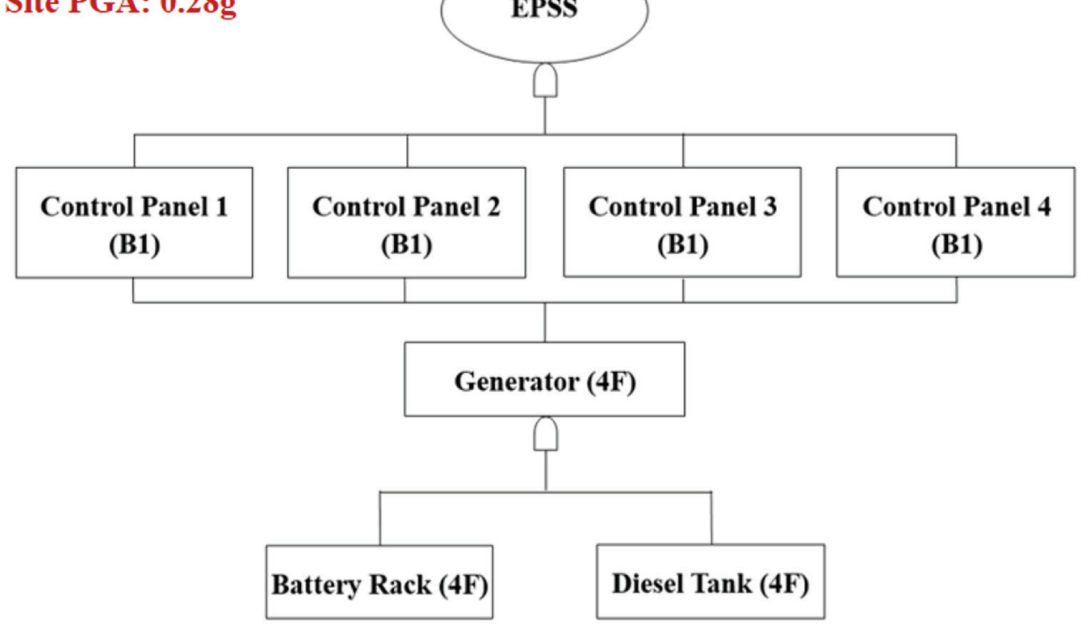

< Hospital D >

Site PGA: 0.67g

EPSS

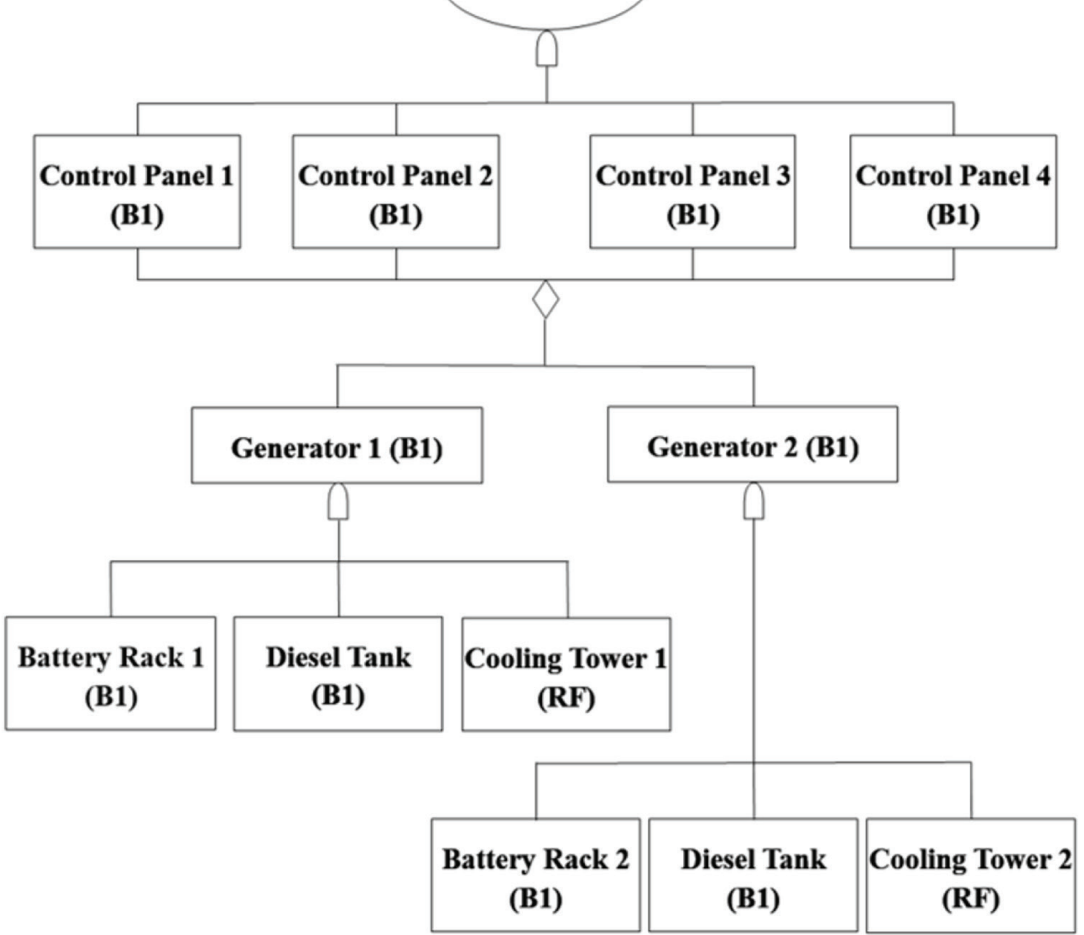

Figure 2: (Continued) 
two generators used the same diesel tank. The failure path must be considered in the calculation of the probability. We took hospital A as the example case. The detailed process of our computation is shown in the following section.

\subsection{Example case: Hospital A}

The EPSS in hospital A had two generators that shared the same diesel tank. Therefore, the generator subsystems were not operated independently. Equations (2) and (3) cannot entirely solve this problem. The failure path must be considered for both subsystems. Furthermore, the peak floor acceleration (PFA) must include the acceleration amplification effect. In our study, the building floors were divided into three parts: the amplification factor of bottom part was set at 1.0, the top part was set at 2.0 and the middle part was set at 1.5.

Hospital A was a 9-story building with one basement. The cooling tower was located on the top floor (9F). In the calculation of its failure probability, the acceleration at the top floor was considered to be 2.0 times the PGA. The other components were placed in the basement. The PFA was identical to the PGA at this site. In addition, according to Chuang's report [1], each component may have experienced many seismic losses (PMFs). In our study, we selected the appropriate fragility median in accordance with the post-earthquake investigation. Table 7 shows the PMF, $x_{m}$, PFA, and failure probability for each component in hospital A.

Figure 3 shows the detailed derivation for the failure probability of the EPSS $\left(P_{\text {EPSS }}\right)$. In general, we can obtain the failure probability of the upper event by using eqn (2) or eqn (3) according to the 'and' or 'or' gate. At Step 1, the battery rack and the cooling tower were taken as the lower events. The failure probability of Upper Event $1\left(P_{1}\right)$ was calculated using eqn (2). At Step 2, the diesel bank was not included. The failure probability of a generator subsystem $\left(P_{2}\right)$ was derived through an 'and' gate that was composed of $P_{1}$ and $P_{G}$. At Step 3, the failure probability of upper event $3\left(P_{3}\right)$, which consisted of five control panels, was calculated. Because the two generators shared the same tank, we proposed the failure path shown in Step 4 for calculating the probability $\left(P_{4}\right)$. Finally, we obtained $P_{E P S S}$ by using $P_{3}$ and $P_{4}$, which formed an 'and' gate.

\section{CONCLUSIONS}

Based on the above methodology, the $P_{E P S S}$ for Hospitals A-D were obtained as listed in Table 8 , and they were then compared with the disaster survey. The results exhibit acceptable consistency with the recorded damage status. This can be explained by the following three reasons: (1) The fragility data identified in our study are appropriate for estimating the

Table 7: PMF, PFA and failure probability for each EPSC in hospital A.

\begin{tabular}{llllll}
\hline Component & PMF & & & & Failure \\
Generator & No anchorage of rubber bottom & 0.78 & B1 & 0.45 & $P_{G}=13.6 \%$ \\
Control Panel & Vulnerable to heavy impact & 1.22 & B1 & 0.45 & $P_{C P}=2.3 \%$ \\
Battery Rack & No battery restraints & 0.58 & B1 & 0.45 & $P_{B R}=30.6 \%$ \\
Diesel tank & Unanchored & 0.56 & B1 & 0.45 & $P_{D T}=33.1 \%$ \\
Cooling Tower & No anchorage of bottom brake & 0.91 & $9 \mathrm{~F}$ & 0.90 & $P_{C T}=49.1 \%$ \\
\hline
\end{tabular}




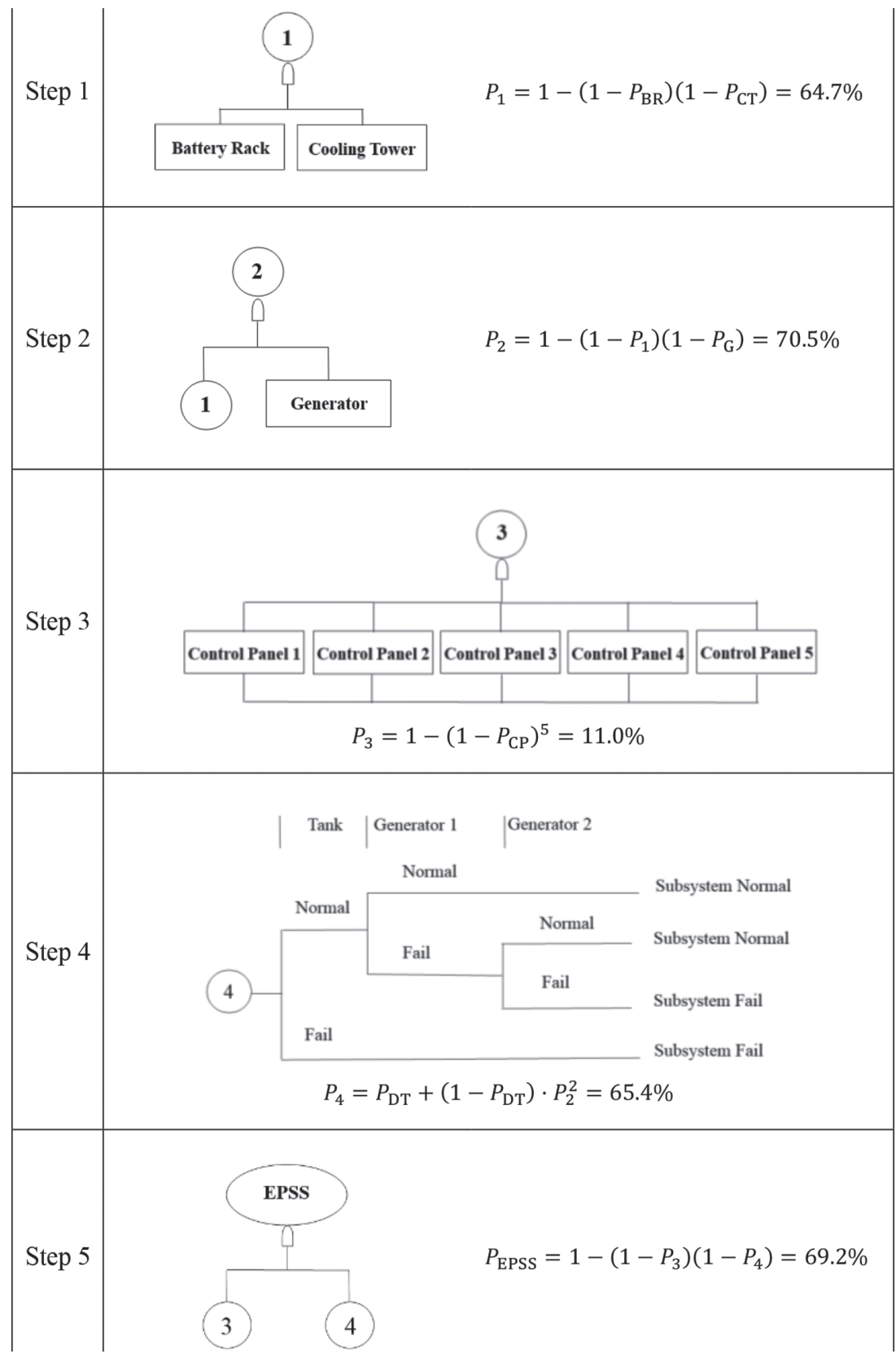

Figure 3: Derivation process of $P_{\mathrm{EPSS}}$ for hospital A.

Table 8: $P_{\text {EPSS }}$ compared with the disaster survey for the Hospitals A-D.

\begin{tabular}{lllll}
\hline Hospital & $\mathrm{A}$ & $\mathrm{B}$ & $\mathrm{C}$ & $\mathrm{D}$ \\
\hline Disaster survey & fail & fail & normal & fail \\
$P_{\text {EPSS }}$ & $69.2 \%$ & $83.8 \%$ & $34.3 \%$ & $97.5 \%$ \\
\hline
\end{tabular}


damage probability for each component impacted by the Chi-Chi earthquake. (2) Logic trees can fully represent the composition of each component. (3) Bottom-up probability analysis combined with failure paths can represent the seismic risk for EPSSs.

\section{ACKNOWLEDGEMENTS}

This work is supported by the Ministry of Science and Technology, Taiwan (R.O.C.) within the projects 106-2119-M-492 -003 and 105-2119-M-492 -004.

\section{REFERENCES}

[1] Chuang, C.C. \& Yao, G.C., Evaluation of seismic capacity of designated hospitals' curative equipment in Tainan region. Department of Emergency Medicine, National Cheng Kung University Hospital, College of Medicine, National Cheng Kung University, Taiwan, 2001.

[2] Multidisciplinary Center for Earthquake Engineering Research (MCEER). Seismic Reliability Assessment of Critical Facilities: A Handbook, Supporting Documentation, and Model Code Provisions, Technical Report MCEER-99-0008, 1999.

[3] Lin, C.H., Liu, X.Q., Kao, L.H., Tsai, C.Y. \& Yang, C.T., Seismic fragility analysis for hospital's emergency power supply equipment. The Thirteenth National Conference on Structural Engineering \& The Third National Conference on Earthquake Engineering, Taiwan, Paper No. 1116, 2016.

[4] Porter, K. \& Ramer, K., Estimating earthquake-induced failure probability and downtime of critical facilities. Journal of Business Continuity \& Emergency Planning, 5(4), pp. 352-364, 2012.

[5] Masri, S., Caffrey, J., Myrtle, R., Nigbor, R., Agbabian, M., Johnson, E., Petak, W., Shinozuka, M., Tasbihgoo, F., Tranquada, R. \& Wellford, L., The FEMA-USC hospital project: nonstructural mitigation in hospitals. The Thirteenth World Conference on Earthquake Engineering, Canada, Paper No. 2480, 2004. 